\title{
STRATEGI KOMITE OLAHRAGA NASIONAL INDONESIA DALAM MENINGKATKAN PRESTASI ATLET DI PROVINSI KALIMANTAN TENGAH
}

\author{
Strategy of the Indonesian National Sports Committee in Improving Athletes' \\ Achievements in Central Kalimantan Province
}

\section{Mambang}

Fatmah

\begin{abstract}
Universitas Muhammadiyah Palangkaraya, Palangka Raya, Central Kalimantan, Indonesia
\end{abstract}

email:

mambang@umpalangkaraya.ac.id

Kata Kunci:
Strategi
Komite Olahraga Nasional
Indonesia
Prestasi Atlet
Keywords:
Strategy
Indonesian National Sports
Committee
Athlete Achievement

Accepted

June 2016

Published

October 2016

\begin{abstract}
Abstrak
Tujuan dari penelitian ini adalah untuk menjelaskan dan mendeskripsikan tentang Strategi Komite Olahraga Nasional Indonesia dalam meningkatkan prestasi atlet provinsi Kalimantan Tengah. Jenis penelitian yang digunakan dalam penelitian ini adalah deskriptif dengan metode penelitian kualitatif. Sumber data dalam penelitian ini adalah data primer yaitu Wakil Ketua Umum KONI, Wakil Sekretaris KONI, Bidang Organisasi dan Manajemen, staf KONI, Atlet dan Pelatih. Sedangkan data sekunder berasal dari dokumen-dokumen resmi yang terkait dengan penelitian ini seperti data perolehan medali cabang olahraga , dan teknik pengumpulan data nya menggunakan wawancara, observasi, dan dokumentasi. Fokus penelitiannya adalah untuk mendapatkan gambaran yang nyata tentang Strategi Komite Olahraga Nasional Indonesia dalam meningkatkan Prestasi Atlet di Provinsi Kalimantan Tengah. Hasil penelitian ini adalah Strategi KONI dalam meningkatkan prestasi atlet di Provinsi Kalimantan Tengah sudah baik, karena dari lima indikator Kinerja ada tiga indikator yang sudah berjalan dengan baik, Responsivitas, Responsibilitas,Akuntabilitas sedangkan dua indikator belum berjalan dengan baik adalah Produktivitas dan Kualitas Pelayanan.
\end{abstract}

\begin{abstract}
The purpose of this study is to explain and describe the Strategy of the Indonesian National Sports Committee in improving the achievements of athletes in Central Kalimantan province. The type of research used in this study is descriptive with qualitative research methods. Sources of data in this study are primary data, namely the Deputy General Chair of KONI, Deputy Secretary of KONI, Division of Organization and Management, KONI staff, Athletes and Coaches. While secondary data comes from official documents related to this research such as sports medal data acquisition, and data collection techniques using interviews, observation, and documentation. The focus of his research is to get a clear picture of the Strategy of the Indonesian National Sports Committee in improving Athlete Achievements in Central Kalimantan Province. The results of this study are that the KONI Strategy in improving the achievements of athletes in Central Kalimantan Province is already good, because of the five Performance indicators there are three indicators that have gone well, Responsiveness, Responsibility, Accountability while the two indicators have not gone well are Productivity and Quality of Service.
\end{abstract}

\section{PENDAHULUAN}

Satu-satunya organisasi keolahragaan nasional yang berwenang dan bertangggung jawab mengelola, membina,mengembangkan dan mengkoordinasikan setiap seluruh pelaksanaan kegiatan Olahraga Prestasi yakni KONI. Berdasarkan hasil observasi KONI masih belum maksimal mencapai target-target yang diinginkan hal ini dapat dilihat dari perolehan medali PON tahun 2012 jumlah 16 medali terjadi penurunan tahun 2016 jumlah II medali. Kinerja KONI secara umum sudah baik akan tetapi masih terdapat beberapa kekurangan yang harus di atasi agar kinerja lebih ditingkatkan lagi.

Dalam hal ini adapun strategi KONI dalam meningkatkan prestasi atlet di Provinsi Kalimantan Tengah diantaranya seperti : mengupayakan peningkatan harkat dan martabat atlet, melakukan pemantauan sarana dan prasarana latihan cabor-cabor memonitoring atlet dan pelatih saat latihan oleh bidang montoring dan 
evaluasi, mengupayakan mengikuti berbagai event sebagai pencapai prestasi lebih baik, memberikan penghargaan kepada pelaku olahraga yang mendapat prestasi atau medali, mengupayakan peningkatan sumber dana pembinaan olahraga prestasi yang berasal dari APBN, APBD, BUMN,BUMD dan swasta, mengupayakan koordinasi, sinergisasi seluruh program pemasalan, pembibitan, pengembangan dan pembinaan olahraga prestasi, menyusun program-program pemasalan, pembibitan pengembangan dan pembinaan olahraga prestasi, secara terpadu didukung ilmu pengetahuan dan teknologi keolahragaan terkini, melakukan kerjasama pembinaan olahraga prestasi dengan Negara adidaya dalam bidang olahraga serta studi banding keluar negeri, KONI-KONI Provinsi, Induk organisasi cabang olahraga melakukan kerjasama dengan industri olahraga dan industri olahraga kreatif lainnya dalam rangka menunjang pembinaan olahraga prestasi, serta mengevaluasi kinerja pelaku olahraga. Strategi Komite Olaharaga Nasional Indonesia secara umum sudah baik akan tetapi masih terdapat beberapa kekurangan yang harus diatasi agar Strategi Komite Olahrga Nasional Indonesia (KONI) lebih ditingkatkan lagi.

Strategi merupakan hal penting bagi kelangsungan hidup dari suatu perusahaan untuk mencapai sasaran atau tujuan yang efektif dan efisien, harus bisa menghadapi setiap masalaha-masalah atau hambatan - hambatan datang dari dalam maupun dari luar. Menurut Anthony, Parrewe dan Kacmar, strategi dapat didefinisikan sebagai formulasi misi dan tujuan organisasi, termasuk di dalamnya adalah rencana aksi (action plans) untuk mencapai tujuan dengan secara eksplisit mempertimbangkan kondisi persaingan dan pengaruhpengaruh kekuatan di luar organisasi yang secara langsung atau tidak berpengaruh terhadap kelangsungan organisasi (Nainggolan, 2008 : 10).

Menurut Rue \& Byars (Pasolong, 2007:175) bahwa kinerja adalah sebagai tingkat pencapaian hasil.
Selanjutnnya menurut pendapat Widodo (2014:16I) bahwa kinerja adalah melakukan sesuatu kegiatan dan menyempurnakannya sesuai dengan tanggungjawabnya dengan hasil sesuai dengan yang diharapkan. Lembaga Administrasi Negara Indonesia disingkat LAN - RI dalam Herbani Pasolong (2007:175) merumuskan kinerja adalah gambaran mengenai tingkat pencapaian pelaksanaan suatu kegiatan, program, kebijaksanaan dalam mewujudkan sasaran tujuan, misi dan visi organisasi

Dwiyanto dalam Pasolong (2010:178) memperoleh beberapa indikator yang digunakan untuk mengukur kinerja pegawai, yaitu:

I. Produktivitas, yaitu tidak hanya mengukur tingkat efisiensi, tetapi juga mengukur efektivitas pelayanan.

2. Kualitas pelayanan, yaitu cenderung menjadi penting dalam menjelaskan kinerja organisasi pelayanan publik. Menurut Dwiyanto kepuasan masyarakat terhadap layanan dapat dijadikan indikator kinerja organisasi publik, keuntungan utama menggunakan kepuasan masyarakat sebagai indikator kinerja adalah informasi mengenai kepuasan masyarakat seringkali tersedia secara murah dan mudah

3. Responsivitas, yaitu kemampuan birokrasi untuk mengenali kebutuhan masyarakat, menyusun agenda dan prioritas pelayanan, dan mengembangkan program-program pelayanan publik sesuai dengan kebutuhan masyarakat dan asprirasi masyarakat. Secara singkat responsivitas disini menunjuk pada keselarasan antara program dan kegiatan pelayanan dengan kebutuhan serta aspirasi masyarakat.

4. Responsibilitas, yaitu menjelaskan bahwa apakah pelaksanaan kegiatan birokrasi publik itu dilakukan sesuai dengan prinsip-prinsip administrasi yang benar dengan kebijakan birokrasi.

5. Akuntabilitas, yaitu menunjuk seberapa besar kebijakan dan kegiatan birokrasi publik tunduk pada para pejabat politik yang dipilih oleh rakyat. Asumsinya adalah bahwa para pejabat politik 
tersebut karena dipilih rakyat, dengan sendirinya akan selalu memprioritaskan kepentingan publik.

\section{METODOLOGI}

Dalam hal ini Peneliti menggunakan pendekatan penelitian kualitatif karena peneliti ingin mengetahui apa yang tersembunyi pada fenomena yang sulit untuk diketahui dan dipahami dan untuk memperoleh informasi faktual dan akurat serta pemecahan masalah pada saat penelitian dilakukan sedangkan permasalahan yang diteliti sangat kompleks dinamis dan penuh makna sehingga sangat cocok jika menggunakan metode penelitian kualitatif yang di harapkan mampu memberikan penjelasan tentang fenomena tersebut dengan menggunakan instrumen penelitian yaitu peneliti sendiri.

\section{HASIL DAN PEMBAHASAN}

Berdasarkan hasil penlitian tentang Kinerja KONI dalam meningkatkan prestasi atlet di Provinsi Kalimantan Tengah dan berdasarkan kesesuaian dengan indikator Dwiyanto dalam Herbani Pasolong maka dijelaskan sebagai berikut:

\section{Produktivitas}

Dari hasil penelitian bahwa KONI Provinsi Kalimntan Tengah telah membuat program dalam menunjang prestasi dengan mengikuti berbagai event untuk mencapai target-target yang diinginkan KONI adapun program yang dibuat seperti : mengikuti Kejuaraan Daerah (Kejurda), Kejuaraan Nasional(Kejurnas), Pekan Olahraga Propinsi(Porprov), Pra PON dan PON sebagai penunjang prestasi dalam mendapatkan hasil yang baik. Selain mengikuti berbagai event atlet dan pelatih juga selalu latihan untuk medapatkan hasil yang maksimal. Hasil yang didapat seperti Emas, Perak dan Perunggu, Dalam hal ini adapun strategi KONI dalam meningkatkan prestasi atlet di Provinsi Kalimantan Tengah diantaranya seperti : mengupayakan peningkatan harkat dan martabat atlet, melakukan pemantauan sarana dan prasarana latihan cabor-cabor memonitoring atlet dan pelatih saat latihan oleh bidang montoring dan evaluasi, mengupayakan mengikuti berbagai event sebagai pencapai prestasi lebih baik, memberikan penghargaan kepada pelaku olahraga mengevaluasi kinerja pealaku olahraga.

Kualitas Pelayanan

Dari hasil penelitian yang dilakukan diketahui bahwa pelayanan di KONI Provinsi Kalimantan Tengah masih belum sesuai dengan indikator kualitas pelayanan, hal ini dikarenakan sarana dan prasana yang digunakan Atlet dan Pelatih masih belum memadai, peralatan yang digunakan masih terbatas begitu juga dengan tempat yang digunakan, sarana dan prasarana yang digunakan masih belum memadai di banding dengan daerah lain dari hasil wawancara hal ini dikarenakan karena keterbatasan dana.

Responsivitas

Dari hasil penelitian yang dilakukan bahwa pihak KONI Provinsi Kalimantan Tengah selalu menanggapi dengan baik dan cepat keluhan yang disampaiakan atlet dan pelatih terkait tentang bantuan cabor seperti dana untuk mengikuti event.

\section{Responsibilitas}

Berdasarkan hasil penelitian penelitian tentang Strategi KONI dalam meningkatkan prestasi Atlet di Provinsi Kalimantan Tengah sudah sesuai dalam aturan UndangUndang No. 3 Tahun 2005 tentang penghargaan. Hal ini dilihat dari hasil penelitian yang didapat ketika program/target tercapai maka yang diperoleh seperti Bonus, medali, reword/penghargaan, rumah, jaminan pekerjaan untuk atlet berprestasi.

\section{Akuntabilitas}

Dari hasil penelitian pertanggungjawaban dari pihak KONI Provinsi dalam meningkatkan prestasi atlet membuat program untuk atlet dan pelatih di buat oleh 
KONI dan menentukan target-target atas kesepakatan bersama dalam hal ini program yang dibuat seperti Kejurnas, Porprov, PON sebagai untuk mencapai target-target dan sebagai pelaksana cabor-cabor. adapun upaya yang dilakukan dalam meningkatkan prestasi melalui pemantauan sarana dan prasarana latihan cabang olahraga, memonitoring saat atlet dan pelatih, serta mengikuti event yang sebagai pencapaian prestasi lebih baik, memberikan penghargaan kepada pelaku olahraga yang mendapat prestasi / medali dan mengevaluasi kinerja pelaku olahraga

\section{KESIMPULAN}

Berdasarkan hasil penelitian dan pembahasan disimpulkan bahwa Kinerja KONI Provinsi Klimantan Tengah sudah baik, karena dari lima indikator yang tidak maksimal ada dua indikator yaitu produktivitas, kualitas pelayanan, sedangkan responsivitas, responsibilitas, akuntabilitas sudah maksimal. Diharapkan KONI Provinsi Kalimantan Tengah dapat menambah sarana dan prasarana, Membuat event untuk cabor-cabor mengikuti event agar jam terbang semakin banyak, prestasi yang didapat juga lebih baik, memperhatikan atlet yang berprestasi karena atlet merupakan putra daerah/ yang patut dihargai perjuangannya dalam mendapatkan prestasi/medali. Selain itu juga diharapkan KONI Provinsi Kalimantan agar memperhatikan pelatih juga diikutkan dalam latihan tingkat pelatih sehingga ilmu yang didapat juga bertambah /berkembang dan memperhatikan pelatih khususnya karena tanpa pelatih atlet tidak bisa mengembangkan kemampuan yang dimilikinya. Terakhir, diharapkan agar pemerintah, Pengurus KONI,pelatih dan Atlet dapat bekerjasama dalam membangun prestasi yang lebih baik lagi khususnya Provinsi Kalimantan Tengah (Palangka Raya).

\section{REFERENSI}

Achmad S. Ruki. 2002. Sistem Manajemen Kinerja.jakarta: PT.Gramedia Pustka Utama.

Fahmi, Irham. 20I3. Manajemen Kinerja Teori dan Aplikasi. Bandung : PT. Alfabeta.

Mambang, M., Harry, W.F. 2016. Implementasi Kebijakan Gelandangan, Pengemis, Tuna Susila Dan Anak Jalanan Di Kota Palangka Raya Provinsi Kalimantan Tengah. Pencerah Publik. 3(2): I-8.

Noor, Juliansyah. 20I3. Penelitian Ilmu Manajemen Tinjauan Filosofis dan prakti. Jakarta : Kencana Prenada Media Grup

Pasolong, harbani. 2010. Teori Administrasi Publik. Bandung: CV.Alfabeta.

Sugiyono. 2015. Metode Penelitian Kuantitatif,Kualitatif dan R \& D Bandung: Penerbit Alfabeta.

Wibowo. 2013. Manajemen Kinerja Edisi 4. Jakarta : PT.Raja Grafindo Persada

Undang -Undang Nomor 3 Tahun 2005 tentang Sistem Keolahragaan Nasional. 